\title{
التداخل الاجناسي بين السيرة الذاتية والقصة في نقد السيرة الذاتية
}

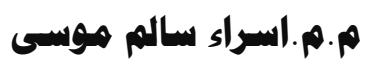 \\ جاهعة القادسية/كلية التربية}

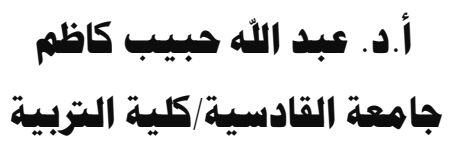

\section{الخلاصة}

على الرغم من الحرية التي يتمتع بها القاص في استعمال مخيلته في عمله الفني ، فإن ذلك لا

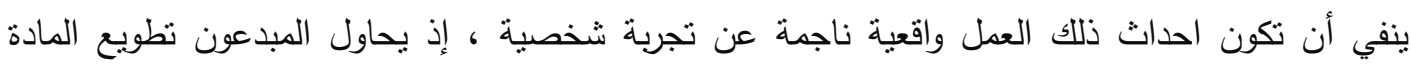

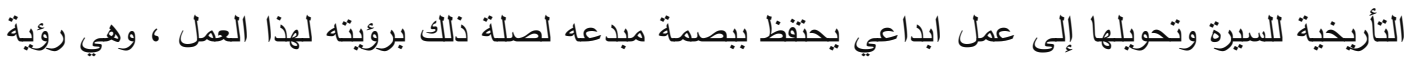

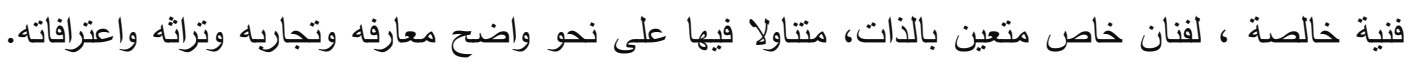

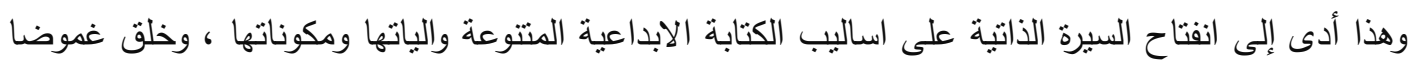

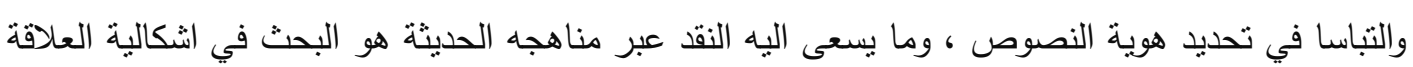

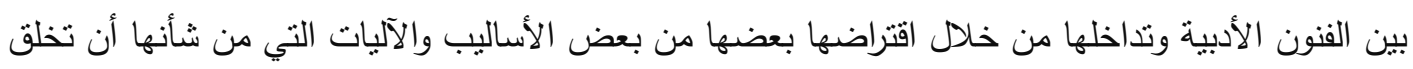

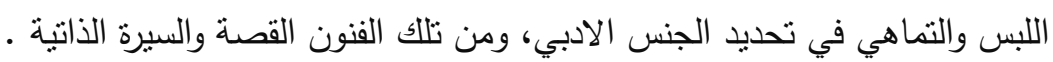

\section{إشكالية تداخل الجنسين}

ومع خصوصية السيرة الذاتية التأريخية والواقعية ، إلا أنها تقترب من القصة فكلتاهما تتهض على القى

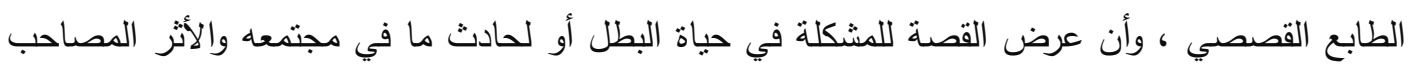

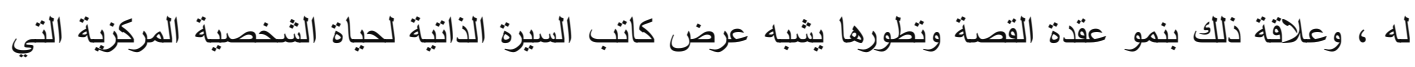

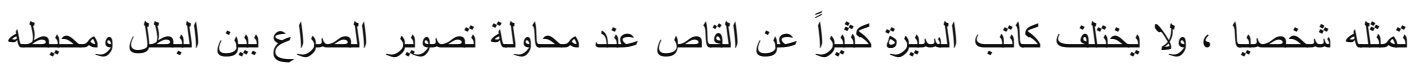

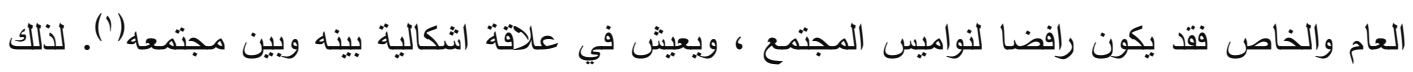

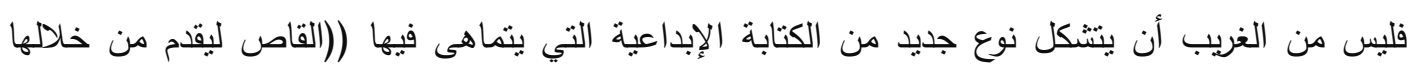

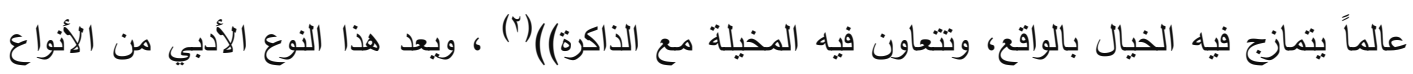

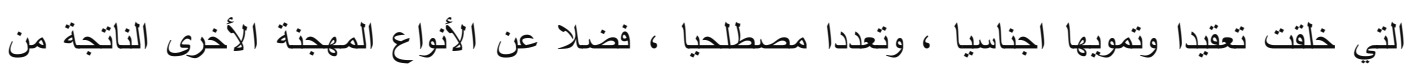


تلاقح السيرة الذاتية وغيرها من الاجناس الأدبية والتي بحث النقاد والدارسون في اشكاليتها المصطلحية والمفهوماتية، الا ان الدكتور محمد صابر عبيد يرى أن اعقدها نوعا هو الناتج من علاقة التداخل بين السيرة الذاتية والقصة بشكل عام والقصة القصيرة بشكل خاص، إذ ((بعد الالتباس العميق الحاصل بين التجربة الثخصية السيرذاتية للقاص وتجربة الإبداع النصني القصصي من أعقد الالتباسات الإشكالية في جوهر العمل القصصي، ذلك أن فن القصة القصيرة من أكثر الفنون الكتابية استجابة للنزعة الذاتية وتعاطيا مع التجارب الثخصية للقاص، بعل ضغط التجربة السيرذاتية من جهة واغراء النوع الكتابي لحساسية التجربة من جهة أخرى ، وربما من الصعب الفصل في هذه القضية لأن الالنباس الإشكالي عميق وشائك، وهو في

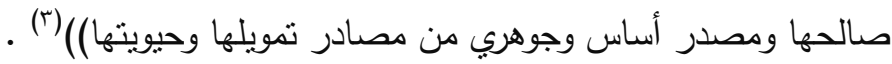

وهنالك من يرى خلاف ذللك الرأي كون فضاء القصة والقصة القصيرة لا يتسع للبوح في تفاصيل الحياة الثخصية ، فخليل شكري يرى أن ((القصة بشكل عام والقصة القصيرة بشكل خاص لا يمكن أن تستوعب سيرة الذات بحكم صغر مساحتها))(؛)، وهو في ذللك يحتكم إلى تعريف لوجون للسيرة الذاتية بأنها ((حكي استعادي نثري يقوم به شخص واقعي عن وجوده الخاص، وذلك عندما يركز على حياته الفردية

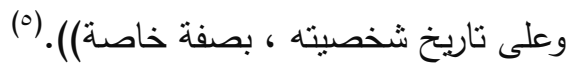

ومع ذلك فهو لا يعترض على فكرة التهجين أو التداخل بين الفنين ، لذلك يحاول معالجة هذا الاشكال بأن تحمل القصة جانبا أو أجزاءً من سيرة الحياة ، وليس الحياة بأكملها وبهذا التكثيف من الممكن أن يكون فضاء القصة قابلا للتلاقح مع السيرة الذاتية ، كما يستعمل الثاعر التكثيف و الإيجاز في إيراد اجزاء من سيرته في قصيدته ، إذ يقول: ((وبما أن النص القصصي السيرذاتي بمفرده - على الرغم من كل المرتكزات التي يحملها - لا يستطيع سرد سيرة الذات، لذا فان تعريف لوجون لا يمكن تطبيقه على النص القصصي ما لم نشفعه ببعض التغييرات كي يتتاسب مع طبيعة النص شأنه في ذلك شأن القصيدة السيرذاتية)(ا) ، ويمكن القول إن تسويغ خليل شكري لمناسبة هذا التلاقح الاجناسي يشمل علاقة السيرة الذاتية مع الفنون الأدبية الأخرى وإن اتسعت فضاءاتها للبوح بالسيرة الذاتية، إذ وجدنا من خلال قراعتتا في الدراسات والاعمال النقدية التي تتاولت علاقة السيرة الذاتية بالرواية أو علاقتها بالثعر، أن تلك الدراسات

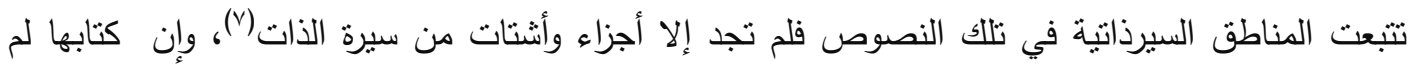
يبثوا فيها كل جوانب الحياة ، وإنما استثروا منها بعض التجارب الذاتية في بناء عوالم يمتزج فيها الواقع 
بالخيال، وأغلب تلك الاعمال مثلت صيغا هروبية أراد الكتاب التماهي خلفها للخلاص من رهبة البوح

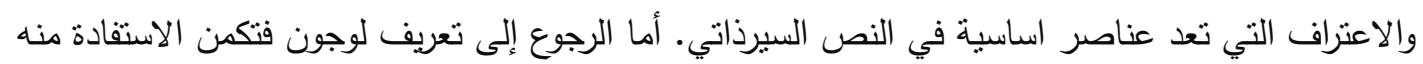

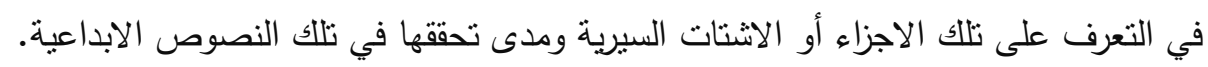

وإذا كان هناك حضور كلي للسبرة الذانية فإن ذلك يعود إلى اكتتاز تلك السيرة بالتجارب الذانية

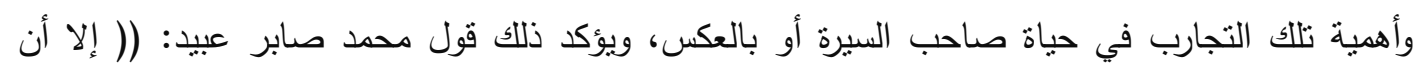

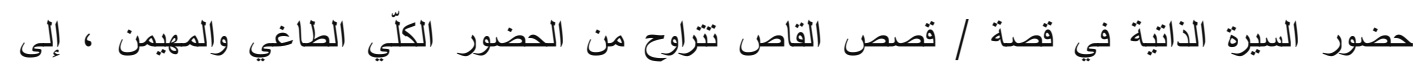

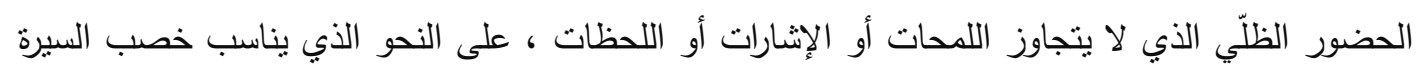

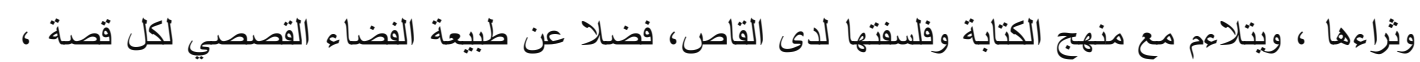

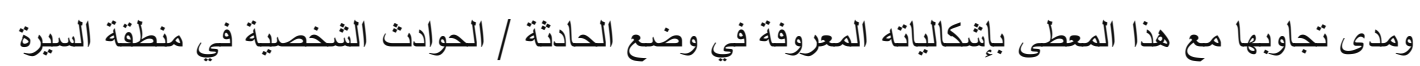

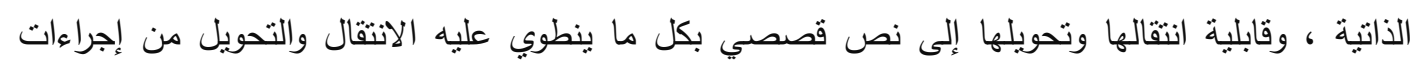

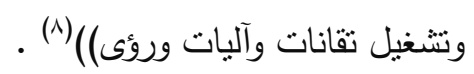

إن هذا النوع من الكتابة يتطلب وعيا بالكتابة السيرذاتية ، إذ يكون بالإمكان رسم مسارات الذات

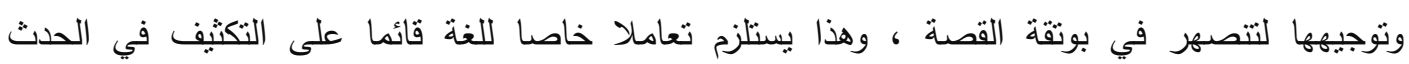

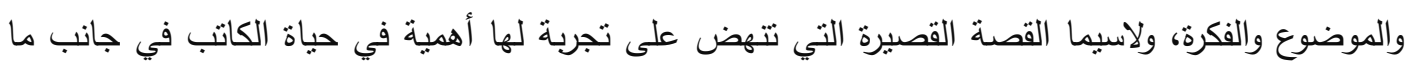

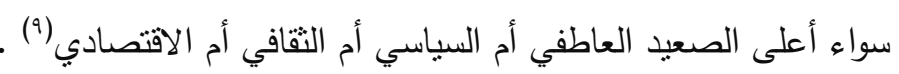

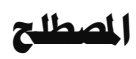

إن أهم ما يجدر بنا توضيحه هو البحث في المصطلح الذي أطلق على هذا النوع الهجين ، وإذا

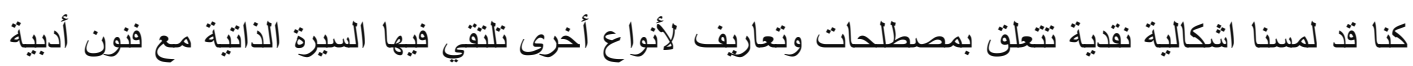

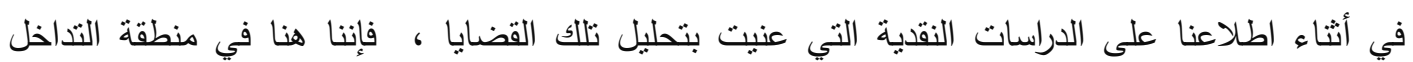

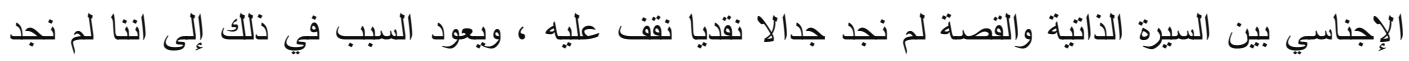

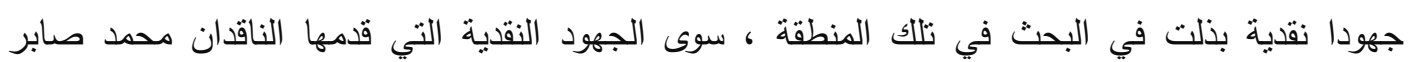

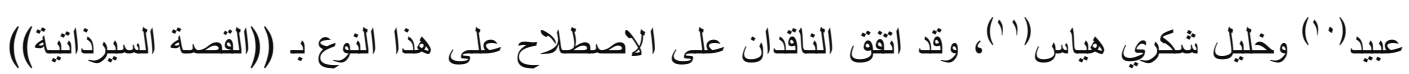

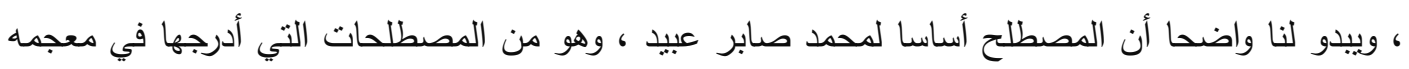


الذي أنجزه وخصصه للتعريف بمصطلحات السيرة والأنواع القريبة منها والمهنة معها والذي سجل أول ورود للمصطلح فيه، أما خليل شكري فقد اتبع عبيد في هذا الاصطلاح دونما ان يكون له ملاحظة تذكر حول

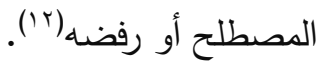

\section{التعريف}

أما تعريف هذا النوع فقد عرفه محمد صابر بأنه: ((سرد استعادي فني ينهض به راوٍ سيرذاتي، يفيد

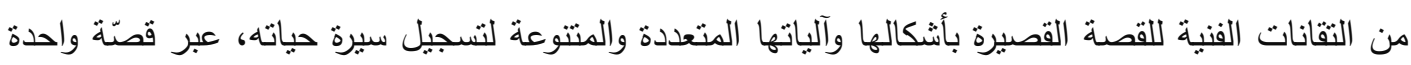
طويلة تحتثد فيها الأحداث وتتركز بحيث تسمح على نحو ما إظهار الثكل الترتيبي التصاعدي للسيرة

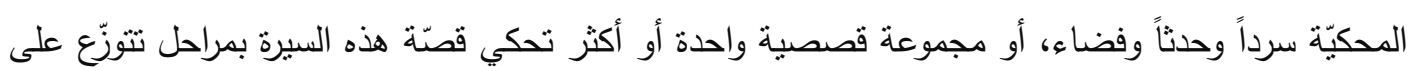
القصص وحسب المراحل الزمنية التي يجدها الراوي مناسبة وصالحة فنباً للعمل القصصي))، وهو تعريف

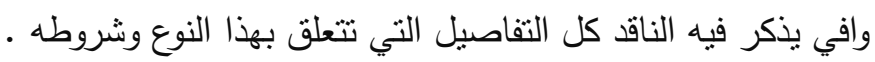

وينوه الدكتور عبيد أن القاص يكتب سيرته في عمل قصصي من خلال نقلها إلى ميدان فني

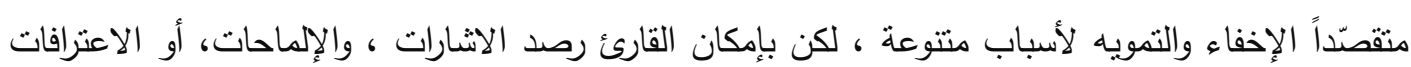

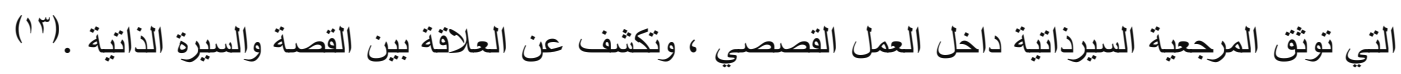
واذا تأملنا في هذا التعريف فإننا سنجده لا يتعارض مع تحقيق المشروع السيرذاتي في النص ، فالناقد يلزم كاتب القصة السيرذاتية بالآتي: - - - السرد فيها استعادي باتجاه الماضي. - - - ان الذي يقوم بالقص راو له وجود واقعي.

- - أن تتسع مساحة النص لسرد تفاصيل مهمة من حياة صاحب السيرة.

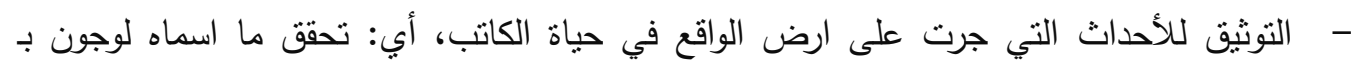

$$
\text { (الميثاق المرجعي). (المثئ) }
$$

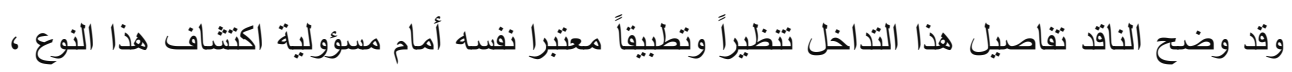
وجدير به أن يضع حداً لما اقترحه ، وكان له جهد تتظبري وتطبيقي في هذا الجانب ، وبذلك فإن الدكتور 
محمد صابر عبيد يعطي حلولا أكثر نضجا لهذا النوع لأن يستوعب سيرة الحياة الشخصية فإذا لم تكن القصة طويلة ، فمن الممكن أن تتوزع سيرة الحياة على مجموعة قصصية كاملة للقاص ، وإن لم تستوعب فأكثر من مجموعة قصصية ، فهو يمنح القاص حرية في سرد تفاصيل كثيرة من سيرته في منجزه القصصي.

أما الدكتور خليل شكري فيحاول أن يجد تعريفا لا يكون فيه هذا النوع الهجين مخالفا لما جاء في تعريف لوجون للسيرة الذاتية ، وفي الوقت نفسه مناسب لحجم القصة بوصفها حاضنة لسيرة القاص الذاتية فيعرفها: ((بأنها قصة استعادية نثرية، يروي فيها القاص كِراً سيرية عن حياته ووجوده، مركزاً حديثه على حياته الفردية، وعلى نكوين شخصيته بالخصوص، مستتداً في كل ذلك إلى آليات المنظومة الذاكراتية)(ـأه (') . وبهذا يمكننا القول إن هذين الناقدين فتحا أفاقا لمن يريد من الدارسين الولوج في دراسة هذا النوع الجديد الذي مازال ارضا بكرا لم تتتاولها أقلام الدارسين بعد ، ومن المؤكد أن هنالك نصوصا تشتحق الدراسة تحقق بها هذا التلاقح الاجناسي بحسب اطلاعنا، وهذا زاد في رغبتتا في عدم اهمال جهود هذين الناقدين في هذا الجانب ، ولاسيما أن جهودهما أضافت ثراء نقديا لساحة النقد السيرذاتي واختيارهما لنصوص أكدت إمكانية هذا التلاقي السيرذاتي - القصصي ، والقيمة الفنية والجمالية لهذا التلاقي.

\section{الدراسات التطبـيشية}

ننتقل إلى القراءة التطبيقية للناقدين ، لمعاينة كيف تحسسا الملامح السيرذاتية في النصوص القصصية ، وما الدلالات التي استتدا إليها في إثبات الحضور السيرذاتي للذات الساردة ، وأي المناهج التي اعتمدت في الاستدلال على ذلك الحضور.

ففي دراسة للناقد محمد صابر عبيد يحاول فيها تقديم نموذج واضح لهذا التداخل في قراعته لقصة (( لحظة واحدة من فضلك )) للقاص عبد الستار ناصر فيصرح بعد سبره لأغوار النص ، وتحليله لبنيته ، أن القاص جعل من ((حياته بمختلف اتجاهاتها وصورها وتتكيلاتها وفضاءاتها وتجاربها ورؤاها مشروع دائم للقص ، فسيرته هي قصته ، وقصته هي سيرته ، وهو يتمتع بحربة كافية ذات مرونة عالية وشفافية انسيابية مدهثة لتحويل كل شيء في حياته إلى سرد قصصي ، فحياته شهادة ، وشهادته سيرة ، وسيرته قصة ، وقصته حياة)(10) مدهنه (10) 
ومن حق القارئ هنا أن يتساءل عن صحة هذا الاستتاج ، لأن القراءة النقدية عادة ما تتطلب

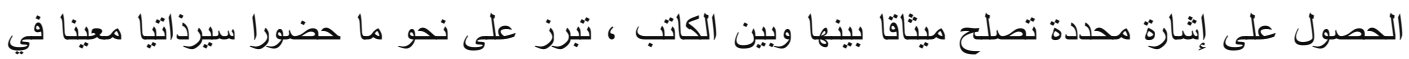

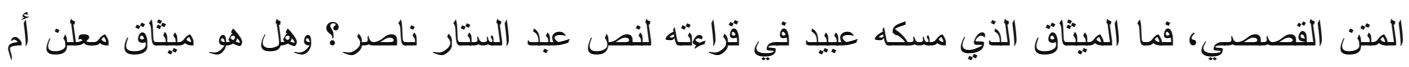

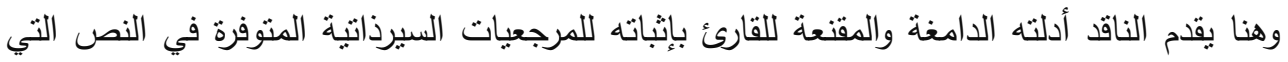

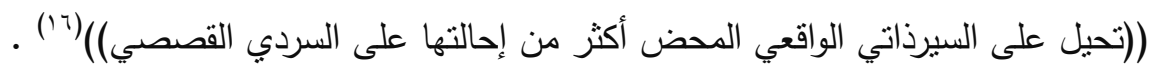

وتتمثل تلك المرجعيات بالآتي:

- - الإحالة إلى الثخصيات بمسياتها ، ذوات المرجعية الواقعية المعروفة في مجتمع القاص وفي دائرة

$$
\text { أصدقائه . الاحالة إلى }
$$

$$
\text { - - - - الأمكنة الواقعية التي حدثت فيها أحداث الحياة. }
$$

- - الأحداث بصورها وتتشكيلاتها وفضاءاتها وتفصيلاتها كما حدثت في حياة الكاتب.

ومن المؤكد أن تعمل نلك المرجعيات على دعم الحس السيرذاتي بوصفها موجهات قرائية تكثق

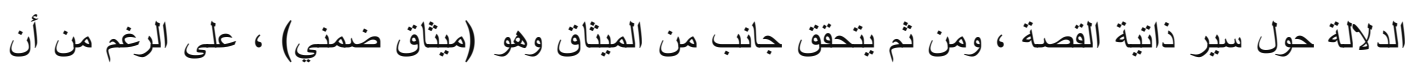

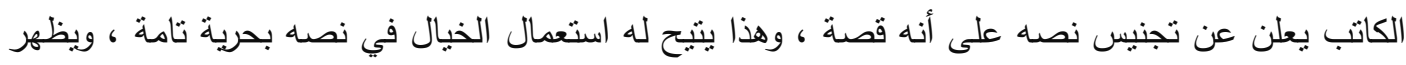
لنا الناقد الإثنارات السيرذاتية على شكل البوم صور تتوزع تلك الصور في في أرجاء قصته مشكلة لوحات قابلة

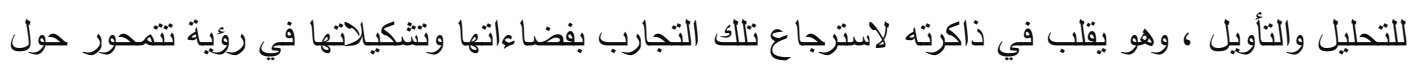

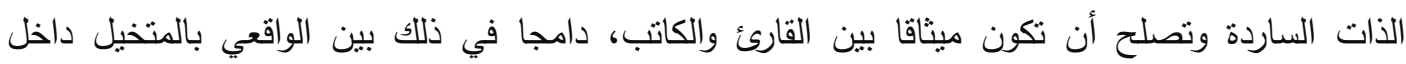

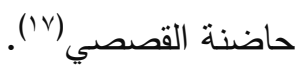

إن كثف الناقد عن تفاصيل لعبة (القاص/ السارد) تمكنه من تحديد المناطق التي استثمر فيها

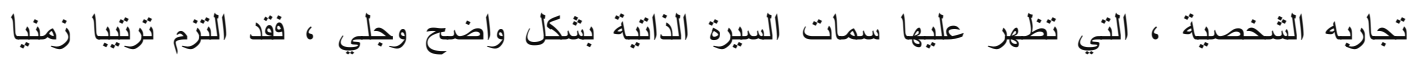

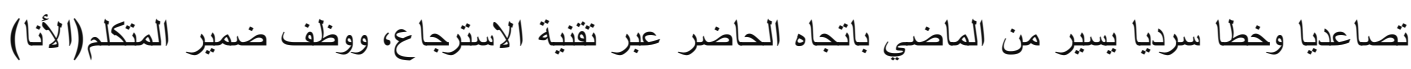
في السرد ، لتأكيد ذاته في ثنايا قصنه. 
أما ملاحظة الناقد حول انتقاء القاص لأجزاء من سبرته(^) ، فهي سمة مشتركة بين المبدعين

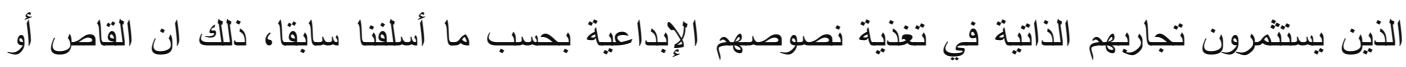

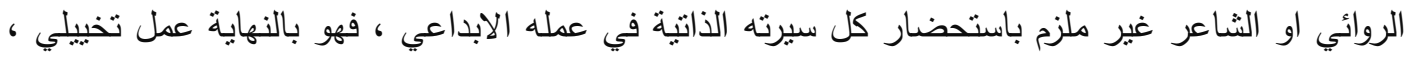

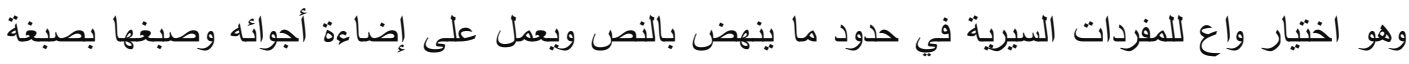

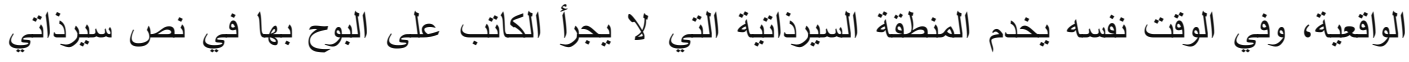

صريح.

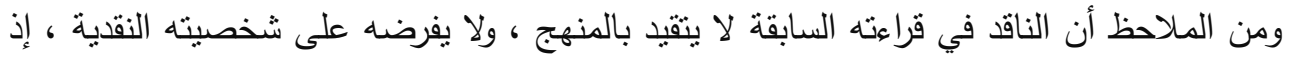

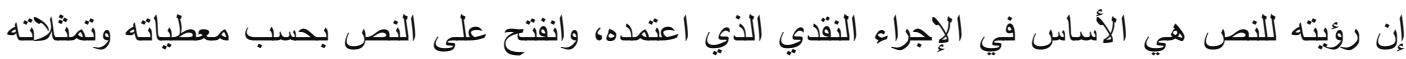

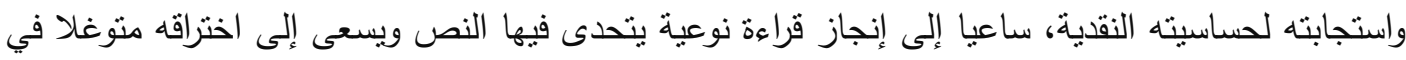
طبقاته وثثاياه ، فقدم رؤية قرائية ناضجة وخصبة حققت فائدة جمالية وفنبة للمنلقي.

ويظهر هذا التذاخل في فضاء القصص القصيرة ، على أن تكتب في مجموعة قصصية كاملة أو أكثر ((تحكي قصّة هذه السبرة بمراحل تتوزّع على القصص وحسب المراحل الزمنية التي يجدها الراوي

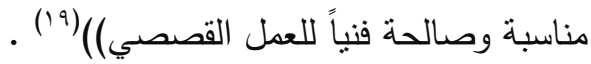

يتكثف لنا هذا التداخل في قراءة اخرى للناقد عبيد في قصة ((طريق دار العجائب)) للقاصة رشيدة

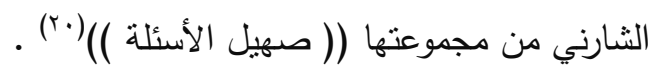

يقرأها الناقد قراءة سيميائية تصف الفعل العلاهي والاثاراتي وأثثه في تصور حساسية الثكل،

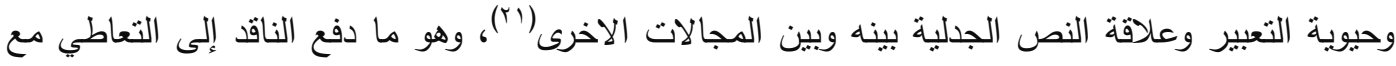

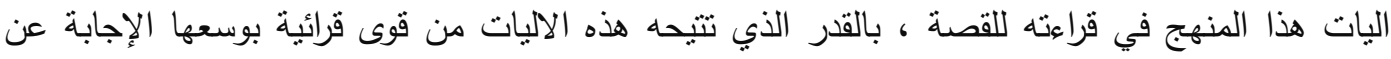

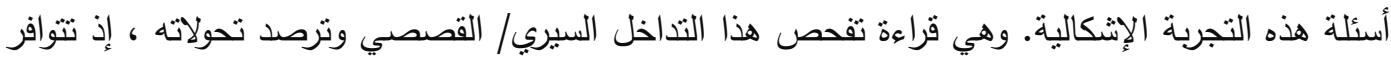

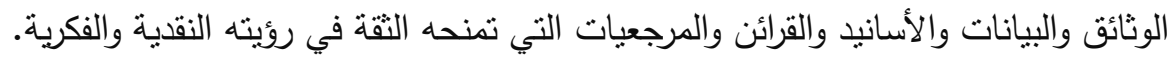

يخبرنا الناقد أن الكاتبة استطاعت أن تستثر أكثر من أداة لتسخيرها في خدمة المنطقة السيرذاتية ، وأهمها (عتبة العنوان) بوصفه موجها قرائيا ، وذهاب الراوي إلى التركيز على الثخصية المركزية 
(الانثوية) المتمنلة بشخص الكاتبة و تجنيد الضمير السردي الأنثوي الذي يخضع لتحوّلات في موقع الراوي

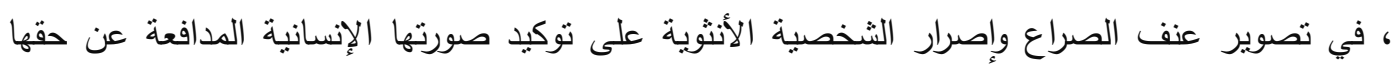

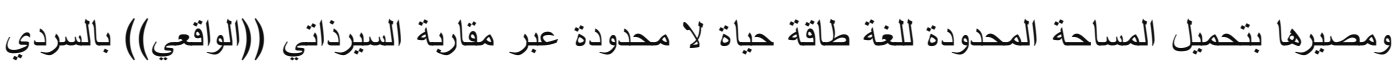

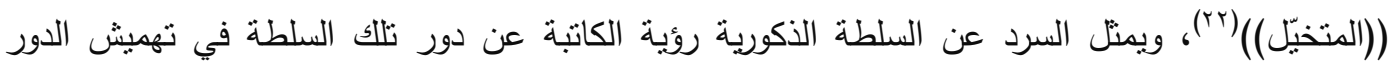
الانثوي بكل ما اعتراه من ضروب القمع والاضطهاد وخنق الإرادات.

وقد تمكن الناقد من رصد التواريخ والأمكنة والثخصيات المكثفة مع دلالاتها الذاكراتية المنصلة

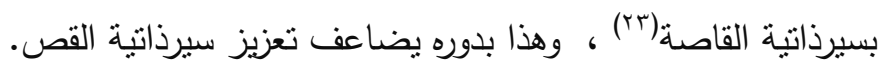

أن قراءة الناقد لنص رشيدة الثارني لا تقوم على المقارنة والمقايسة بين حياة المؤلف ونصه

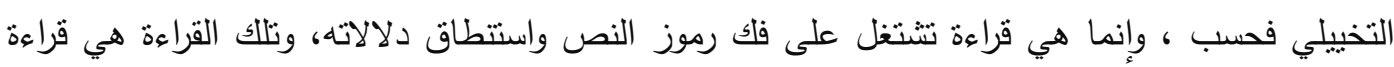

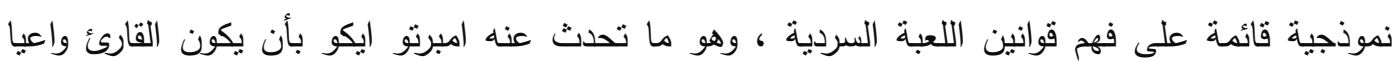
بطبيعة التلميحات والتصريحات التي يوجهها الكاتب له والتي تتكل طبيعة العقد القرائي (؟؟).

ويستتد الدكتور خليل شكري في اختياره لمجموعتي كمال عبد الرحمن القصصية بتحديد عدد من

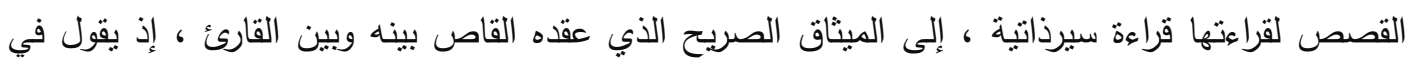

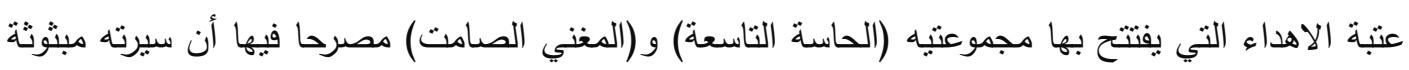
في قصصه : ((إليك جزءاً من حياتي مبثوثة في ثنايا قصصي))(ro) .

ويحلل الناقد قصة (ما أتاني من حديث عبد جدو) تحليلا في بنية النص والتقاط ما هو مخفي بين ثنايا وتخوم تلك البنية، محاولا تحسس المنطقة السيرذاتية فيها المتمثلة بأهم مرنكزات السيرة الذانية ، فالسية فالسرد

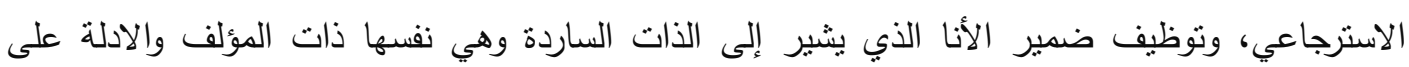

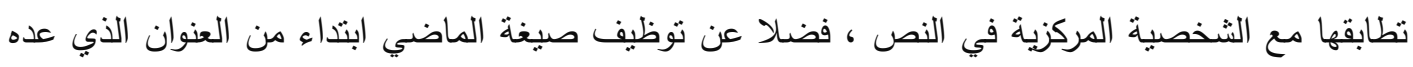

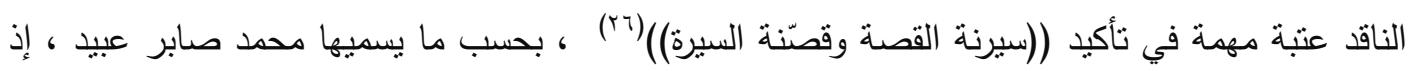

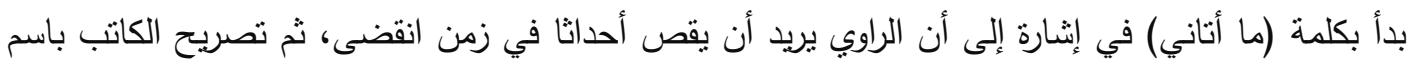

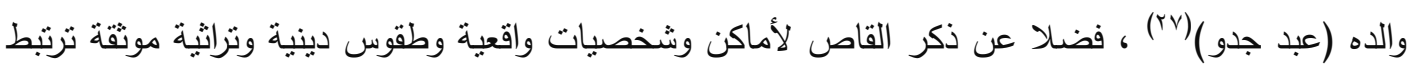

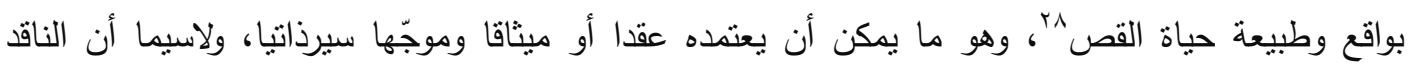


تربطه صداقة بالقاص ، وهذا ما نوه عنه في بحثه هذا ، فيصبح بذلك قادرا على التحقق من صحة كل ما صرح به القاص في نصه ، ومعاينة المنطقة الواقعة بين السيرذاتي والقصصي أي بين الواقع والخيال.

وبذلك استطاع الناقد أن يتبين فلسفة القص عند كمال عبد الرحمن التي تجمع كل الأدوات والتقانات والقيم والذكريات والرؤى في فضاء سردي واحد يجمع بين القصصي والسيرذاتي.

ويتضح لنا أن الناقدين في قراعتها لهذا التداخل في النماذج النصية التي اختاراها للتطبيق فإنهما لم يحاولا إسقاط العالم الخارجي لهؤلاء القصاصين قسرا على اعمالهم القصصية ، وإنما استتدا إلى أدلة تثبت للقارئ هذا الحضور السيرذاتي الجلي في تلك النصوص كما وضحنا سابقا ، إذ أدركا التطور الحاصل في جنس السيرة الذاتية وانفتاحها على الاساليب الابداعية عبر تلك النصوص التي عمد أصحابها إلى تجسيد ذواتهم فيها مستعيدين الماضي ليعيشوه مجددا في قصصهم •

وخليق بنا أن نشير إلى أن هذا التداخل والتضافر ناتج عن الرغبة في الابتعاد عن شبح السيرة

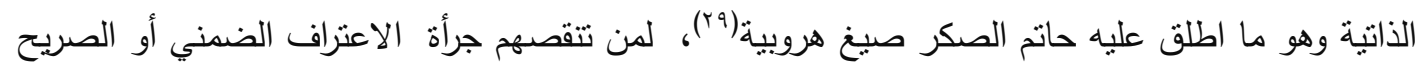
في نص سيرذاتي ، فضلا عن أن السيرة الذاتية مصدر خصب وثري يستقي منه الكتاب في كتاباتهر الإبداعية، مما يمنح النصوص الجديدة حيوية وإشراقا ناتجة عن الاندماج بين فنين ابداعيين، وتظهر جمالية السرد وحساسيته الفنية في التنويع وتطعيم القصصي بالسيرذاتي ثم الإطاحة بالفاصل بين النوعين ليصبح فضاء إبداعيا واحدا له خصوصيته وفنيته.

\section{هوامش البحث ومصادره :}

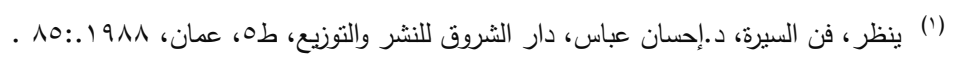

(؟) القصة السيرذاتية في قصص كمال عبد الرحمن، د. خليل شكري هياس ، مجلة آداب الفراهيدي، العدد (1)، السنة الاولى، كانون الاول

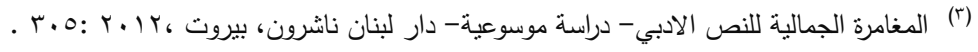

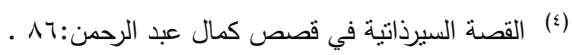

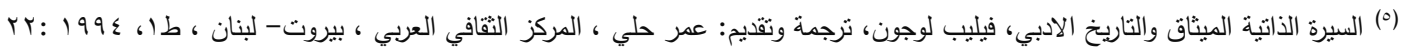




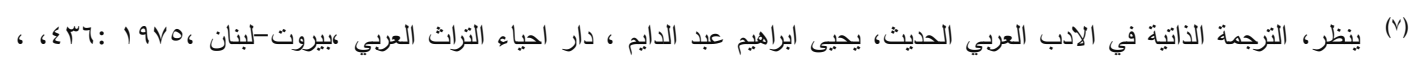

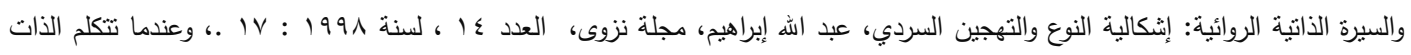

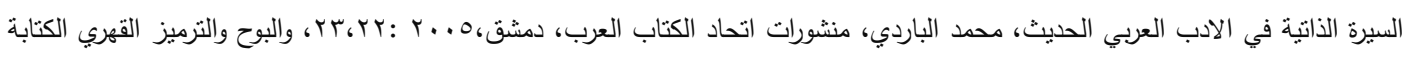

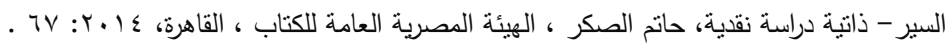

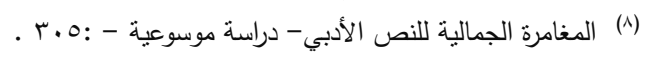

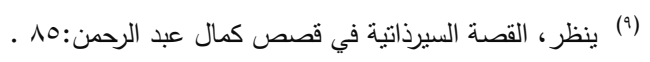

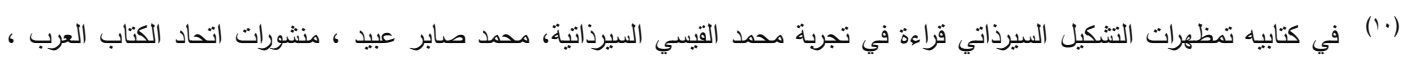

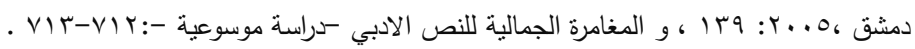

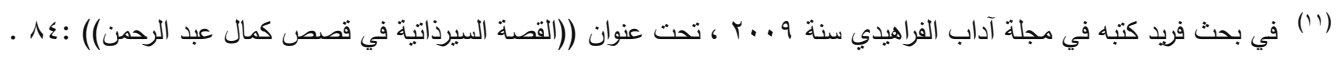

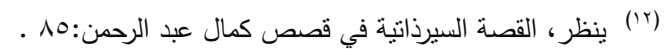

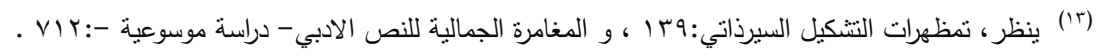

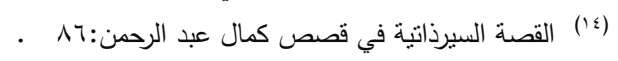

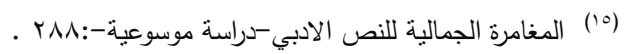
. rar:ن. (17) ( ينظر ، م.ن: (1)

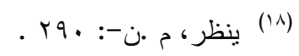

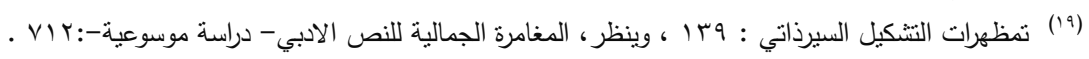

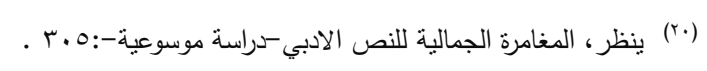

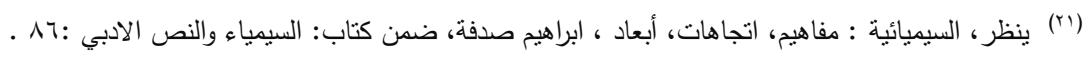

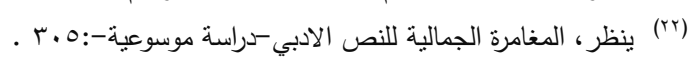

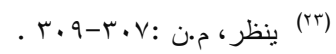

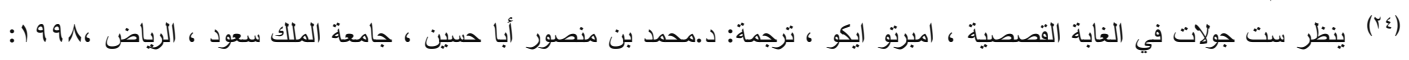

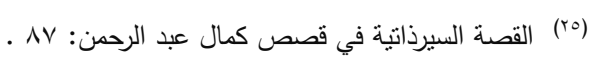

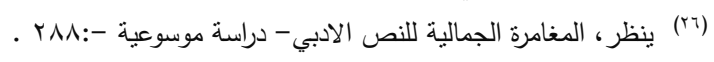

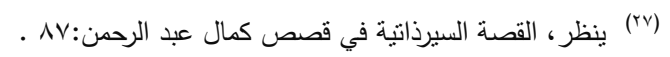

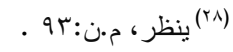

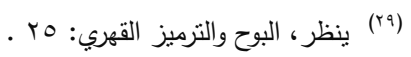

